\title{
Waits for Surgery Following Hip Fracture
}

\section{Temps d'attente pour les chirurgies après une fracture de la hanche}

\author{
by KIRA LEEB, BA, MA \\ Canadian Institute for Health Information \\ Toronto, ON \\ KATHLEEN MORRIS, BA, MBA \\ Canadian Institute for Health Information \\ Toronto, ON \\ LINDA CHOY, CCHRA(C), BCOMM \\ Canadian Institute for Health Information \\ Toronto, ON \\ TRACY JOHNSON, BSC, MBA \\ Canadian Institute for Health Information \\ Toronto, ON
}

\begin{abstract}
Almost all hip fracture patients undergo surgery to repair the fracture. Recent research suggests that timely repair is important for good outcomes following surgery. Patients who had surgical repair of a hip fracture in 2003-2004 were identified using hospitalization data collected by the Canadian Institute for Health Information. Time to surgery was calculated from day of admission to day of surgery. The associations of
\end{abstract}


both patient and system characteristics with waits for surgery were considered. While the majority of patients had surgery on the day of or the day following admission, 29\% waited two days or longer for surgery. Wait times were related to patients' age, hospital size, day of admission and whether patients were transferred.

\section{Résumé}

Presque toutes les personnes victimes d'une fracture de la hanche subissent une chirurgie pour réparer la lésion. De récents travaux de recherche suggèrent qu'une intervention en temps opportun est importante pour assurer de bons résultats après la chirurgie. On a repéré les patients qui ont subi une intervention chirurgicale après une fracture de la hanche en 2003/2004 à l'aide des données sur l'hospitalisation compilées par l'Institut canadien d'information sur la santé. On a ensuite calculé le délai entre la date d'admission et celle de la chirurgie. On a aussi tenu compte de l'association entre les caractéristiques des patients et du système et les temps d'attente pour la chirurgie. Tandis que la majorité des patients ont été opérés le jour même de leur admission à l'hôpital ou le lendemain, $29 \%$ ont attendu deux jours ou plus pour se faire opérer. Les temps d'attente variaient selon lâge des patients, la taille de l'hôpital, le jour de l'admission et si les patients avaient été transférés ou non.

Lmost all hip fracture patients undergo surgery to Repair the
fracture. Recent studies indicate that rates of surgery for these patients are
over 90\% (Orosz et al. 2002; Bottle and Aylin 2006). Given the high rates of surgical intervention, outcomes related to delays in surgery following admission to hospital have received attention from researchers. Several studies have focused on outcomes such as rates of post-operative complications, functional recovery and independence, length of hospital stay and in-hospital mortality (Orosz et al. 2002; Orosz et al. 2004; Weller et al. 2005; Bottle and Aylin 2006). While these studies are not entirely conclusive, improved outcomes have been noted following earlier rather than later surgery (Weller et al. 2005; Orosz et al. 2004; Sund and Liski 2005). In December 2005, Canadian health ministers adopted a common goal of hip fracture repair within 48 hours (Ontario Ministry of Health and Long-Term Care 2005).

Waits for surgery following hip fracture can be divided into a variety of segments. For example, a study of hospital admissions for hip fracture to four hospitals in New York found that $17 \%$ of patients waited more than 24 hours before going to hospital (Orosz et al. 2002). In Ontario - the only province for which wait times associated with emergency department visits are routinely collected by CIHI - in 2004-2005, hip fracture patients had a median length of stay of four to five hours in the busiest emer- 
gency departments prior to being admitted to hospital (CIHI 2006). This paper focuses on a third segment of the wait: waits for surgery following admission to hospital.

\section{Methods}

\section{Data source and study population}

This study relied on hospitalization data from the Canadian Institute for Health Information's Hospital Morbidity Database (HMDB) between April 1, 2003 and March 31, 2004. This patient-specific database contains clinical, demographic and administrative data on acute hospital inpatients from all provinces and territories. The HMDB was used to select patients with a most responsible diagnosis of hip fracture (ICD-10 S72.0, S72.1, S72.2, ICD-9/ICD-9CM 820) and a surgical intervention in the same or contiguous hospitalization (also referred to as the same "episode of care").

Patients were excluded from the analysis if there was no surgical intervention; the institution code was invalid; the health insurance number was invalid; or age was less than 20 or greater than 105 . Also excluded from the analyses were patients whose hip fracture occurred in hospital. For those 65 and older, the rate of occurrence of in-hospital hip fracture is approximately one in 1,124 admissions annually (CIHI 2004).

\section{Data analysis}

Wait times for surgery following hip fracture were calculated in days from the date of index admission to the date surgery was performed. The proportion of those who waited two or more days for surgery was compared to the proportion of those who received their surgery either on the day of admission or on the day following their admission.

Because time of procedure is not available in the HMDB, we cannot determine the number of hours a patient waits between admission and surgery. Given the research evidence suggesting that timely surgery is important, we segmented the study population into two groups: those who received their surgery on the day of admission or the next day, and those who waited two days or more after admission. Those included in the "same or next day" group will all have waits of less than 48 hours following admission as an inpatient. A limitation of the study is that some of the patients in the "two days or more" group may also have post-admission waits of less than 48 hours, if they were admitted late in the day and received surgery early on the second day following admission. For this reason, we considered the distribution of waits associated with those who waited two or more days following admission.

Wait times were calculated by age of patient, day of index admission, hospital size and whether patients were transferred to another facility to have surgery following the index admission. Significance tests were performed where appropriate. 


\section{Results}

Who received surgery?

In 2003-2004, 24,117 patients had surgery following a most responsible diagnosis of hip fracture in Canadian acute care facilities. More than eight out of 10 were 70 years or older. The majority of patients $(71 \%)$ received surgery either on the day of admission or the following day. However, just over 6,940 people (29\%) waited longer for their surgery. While $16 \%$ had surgery two days after admission, the remaining $13 \%$ waited three days or longer and 3\% waited six days or longer. Age was also associated with wait times. Twenty-two percent of patients aged 69 and under waited two days or longer for surgery, whereas of those 70 years and older, $30 \%$ waited this long (chisquare, $\mathrm{p}<.0001$; Figure 1).

\section{Waits associated with system characteristics}

Both day of admission to hospital and hospital facility size (measured by number of beds) were associated with the percentage of hip fracture patients who waited two

FIGURE 1. Proportion of hip fracture patients waiting for surgery by age group

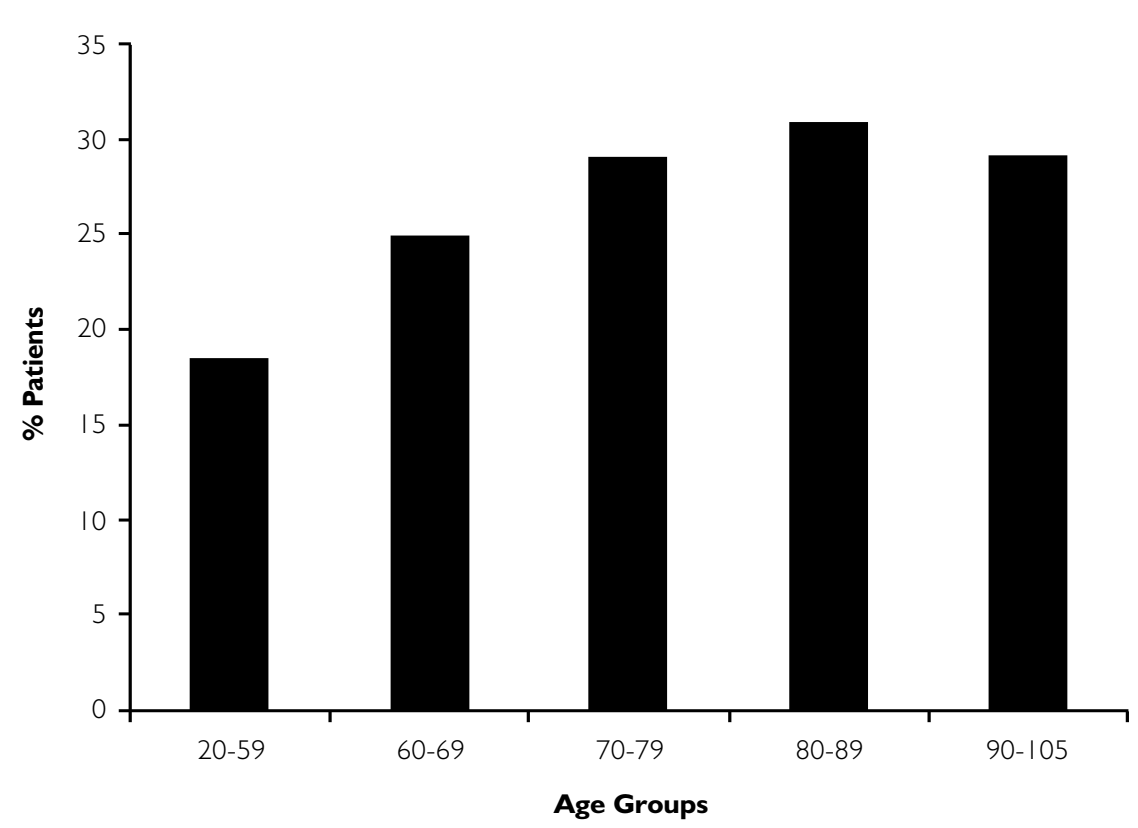


days or more for surgery following their admission. For example, significantly fewer patients admitted to hospital on weekends waited two days or more for surgery (chisquare, $\mathrm{p}<.0001$; Figure 2). Hip fracture patients were more likely to have longer waits for surgery in larger hospitals, with teaching facilities having the highest percentage of patients waiting two days or more (chi-square, $\mathrm{p}<.0001$; Figure 3 ).

FIGURE 2. Proportion of hip fracture patients waiting for surgery by day of the week, 2003-2004

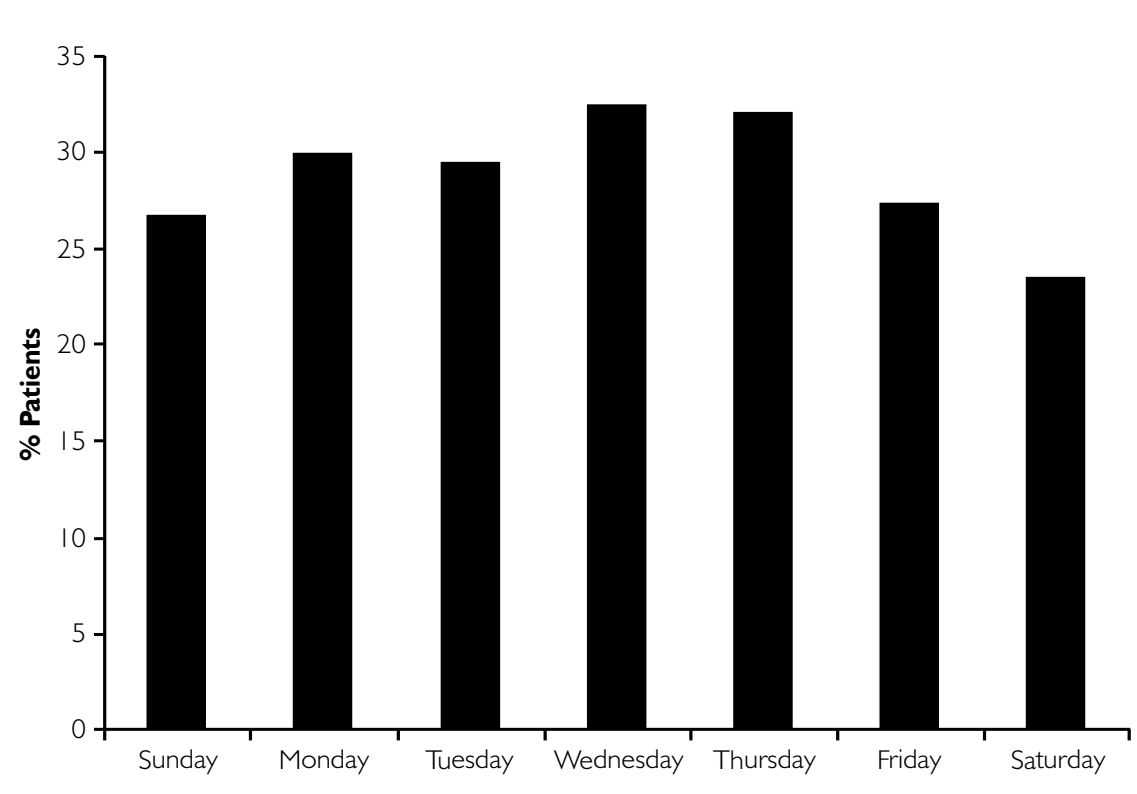

Day of Admission

Source: Hospital Morbidity Database, $\mathrm{CIHI}$.

Surgery to repair hip fractures is almost entirely unplanned. In 2003-2004, close to nine in 10 patients were admitted to hospital through emergency departments. In some cases, the hospital at which the patient first presents may be unable to perform the needed surgical repair or provide other care required. In this situation, some patients may be stabilized in the emergency department and then transferred to another acute care facility (resulting in a single inpatient admission). Other patients may first be admitted to hospital from the emergency department and then transferred to another acute care facility where the surgery is performed (resulting in two inpatient admissions). In 2003-2004, just over 1,350 patients (6\% of all patients) fell 
FIGURE 3. Proportion of hip fracture patients waiting for surgery by facility size

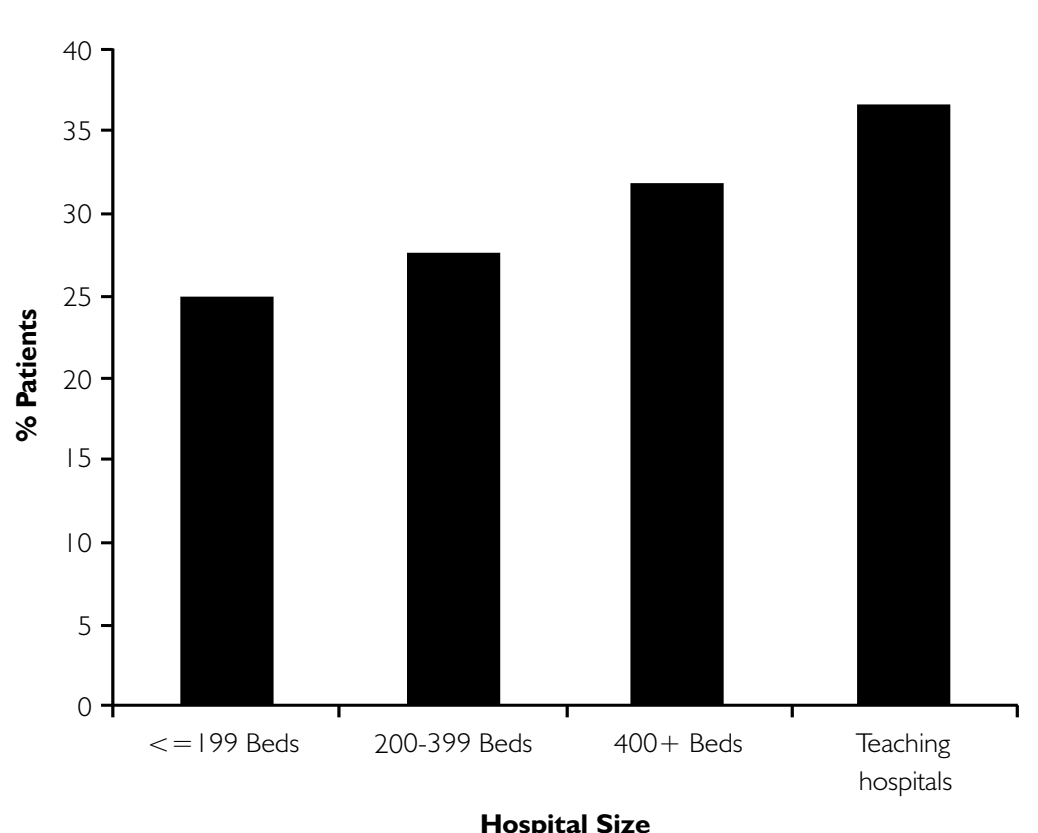

Note: Some institutions from Manitoba and Quebec did not have an assigned peer group; therefore, a total of 5,323 patients were excluded from this analysis by peer group.

Source: Hospital Morbidity Database, CIHI.

into this latter category. When waits to surgery for these transferred patients were compared to patients who underwent surgery at the hospital of their initial admission, almost 2.5 times as many patients (67\%) waited two days or longer for their surgery than those who had surgery at their initial hospital (27\%) (Figure 4).

\section{Conclusion}

While the majority of hip fracture patients received surgery on the day of admission or the day following, close to a third did not $(16 \%$ on the second day after the admission day and $13 \%$ beyond the second day). In this study, older patients were more likely to wait longer. This is consistent with the longer waits for older patients observed in a study of hip fracture patients hospitalized in the United Kingdom, which researchers suggest was related to the increased likelihood of co-morbidities (Bottle and Aylin 2006). Medical stabilization of patients due to associated medical conditions caused the longest delays in surgery in another study (Orosz et al. 2002). With respect to system 
FIGURE 4. Waits for hip fracture repair for transferred vs. non-transferred patients

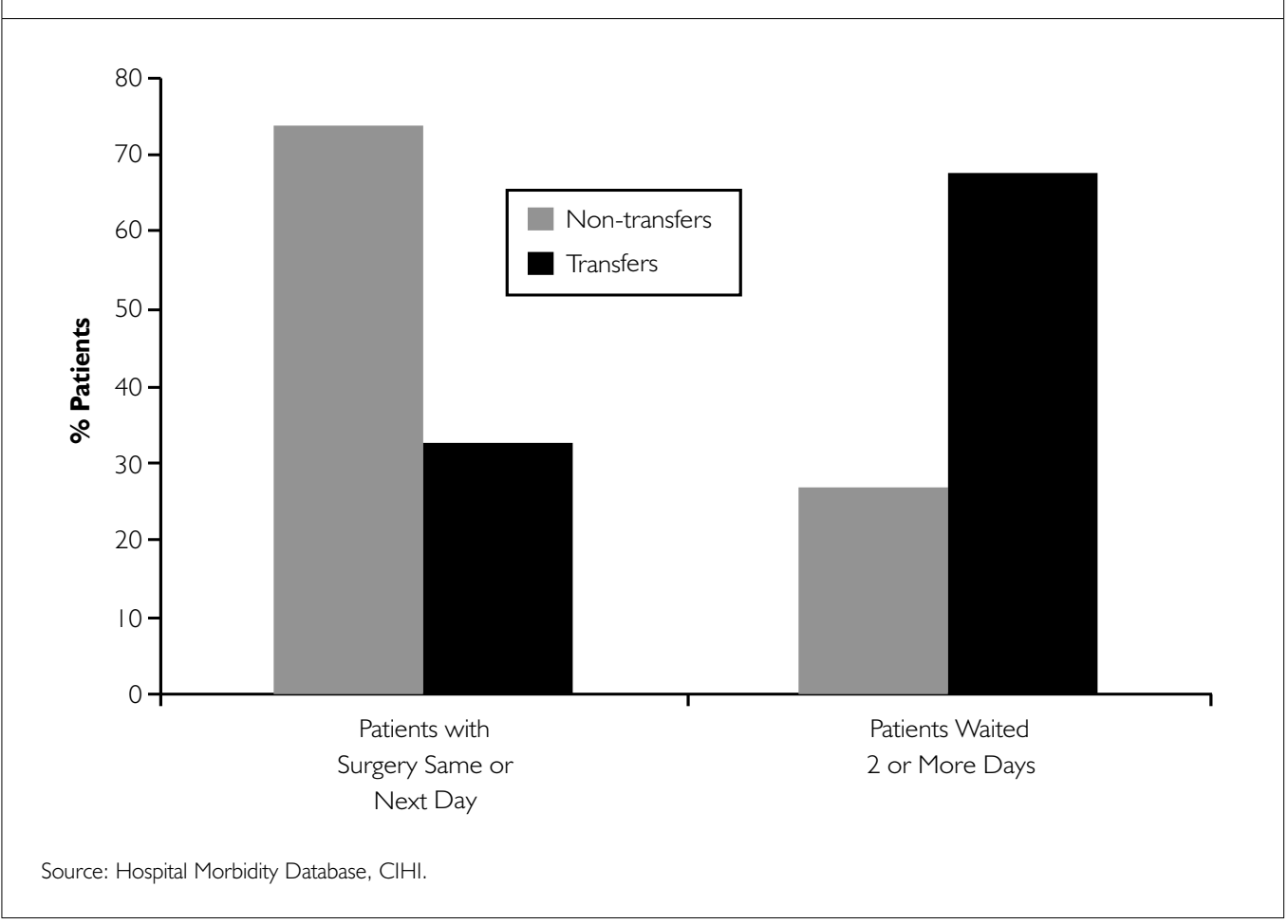

characteristics, size of admitting hospital, day of admission and whether the patient was transferred prior to surgery were all associated with wait times for hip fracture.

This study demonstrates that a significant proportion of patients wait two or more days for surgery. In some studies, delays in surgery have been associated with poorer outcomes. Understanding these and other factors that are associated with longer wait times for surgery following hip fracture can help channel efforts to reduce them and ensure that hip fracture patients are receiving optimal care.

Correspondence may be directed to: Kira Leeb, Senior Project Manager, Health Council of Canada/Conseil canadien de la santé, 90 Eglinton Avenue East, Suite 904, Toronto, Ontario M4P 2Y3; tel: 416-480-7091; email: kleeb@healthcouncilcanada.ca.

\section{REFERENCES}

Bottle, A. and P. Aylin. 2006. "Mortality Associated with Delay in Operation After Hip Fracture: Observational Study." British Medical Journal 332: 947-51.

Canadian Institute for Health Information. 2004. Health Care in Canada. Ottawa: Author. 
Canadian Institute for Health Information. 2006. Based on analyses of National Ambulatory Care Reporting System data 2004-2005. Unpublished results.

Canadian Intergovernmental Conference Secretariat. 2005. A 10-Year Plan to Strengthen Health Care. Retrieved July 13, 2006. <http://www.scics.gc.ca/cinfo04/800042005_e.pdf>.

Ontario Ministry of Health and Long-Term Care. 2005. First Ever Common Benchmarks Will Allow Canadians to Measure Progress in Reducing Wait Times. Retrieved July 13, 2006. <http:// www.health.gov.on.ca/english/media/news_releases/archives/nr_05/nr_121205.html>.

Orosz, G.M., E.L. Hannan, J. Magaziner, K. Koval, M. Gilbert, A. Aufses, E. Straus, E. Vespe and A.L. Siu. 2002."Hip Fracture in the Older Patient: Reasons for Delay in Hospitalization and Timing of Surgical Repair." Journal of the American Geriatrics Society 50: 1336-40.

Orosz, G.M., J. Magaziner, E.L. Hannan, R.S. Morrison, K. Koval, M. Gilbert, M. McLaughlin, E.A. Halm, J.J. Wang, A. Litke, S.B. Silberzweig and A.L. Siu. 2004. "Association of Timing of Surgery for Hip Fracture and Patient Outcomes." Journal of the American Medical Association 291(14): 1738-43.

Sund, R. and A. Liski. 2005. "Quality Effects of Operative Delay on Mortality in Hip Fracture Treatment." Quality and Safety in Health Care 14: 371-77.

Weller, I., E.K. Wai, S. Jaglal and H.J. Kreder. 2005.“The Effect of Hospital Type and Surgical Delay on Mortality After Surgery for Hip Fracture." Journal of Bone and Joint Surgery [British Edition] 87-B(3): 361-66.

\section{Call to Authors}

Data Matters presents brief, focused papers that report analyses of health administrative or survey data that shed light on significant health services and policy issues. Submissions to Data Matters should be a maximum of 1,500 words, exclusive of tables, figures and references, and should include no more than three tables or figures.

\section{Appel aux auteurs}

«Questions de données » présente de brefs articles portant sur des analyses de données administratives sur la santé ou de données d'enquête et qui font la lumière sur d'importantes questions liées aux services et aux politiques de santé. Les articles soumis à «Questions de données » doivent être d'au plus 1500 mots, excluant les tableaux, diagrammes et références et ne doivent pas comprendre plus de trois tableaux ou diagrammes.

For more information contact Rebecca Hart, Managing Editor, at rhart@longwoods.com. 